\title{
INTEGRAÇÃO NO ENSINO MÉDIO: LUTA HEGEMÔNICA PELA SIGNIFICAÇÃO DO CURRÍCULO
}

\author{
INTEGRATION IN HIGH SCHOOL EDUCATION: HEGEMONIC STRUGGLE FOR \\ SIGNIFICATION OF THE CURRICULUM \\ INTEGRACIÓN EN LA ENSEÑANZA SECUNDARIA: LUCHA HEGEMÓNICA POR LA \\ SIGNIFICACIÓN DEL CURRÍCULO
}

\section{Maria Gorete Rodrigues Cardoso ${ }^{1}$ Genylton Odilon Rego da Rocha²}

${ }^{1}$ Doutora em Educação pela UFPA. Docente da Faculdade de Educação da Universidade Federal do Pará (UFPA), Belém, PA, Brasil.

${ }^{2}$ Doutor em Geografia pela USP. Docente do Programa de Pós-Graduação em Currículo e Gestão de Escola Básica da Universidade Federal do Pará (UFPA), Belém, PA, Brasil.

Resumo: O trabalho focaliza os discursos de integração na política curricular brasileira para o ensino médio no período de 1998 a 2012. O objetivo central é compreender a produção dos discursos de integração como luta hegemônica pela significação do currículo, evidenciando o processo articulatório que possibilitou a fixação de determinados sentidos provisórios e contingentes nos textos curriculares. Metodologicamente, a pesquisa se pauta numa abordagem qualitativa e se caracteriza como um estudo bibliográfico e documental. A Teoria do Discurso de Ernesto Laclau (1987, 2011, 2013) e o Ciclo Contínuo de Políticas de Stephen Ball $(1992,1994)$ são aportes estratégicos que subsidiam a investigação. Este referencial teórico-metodológico nos possibilita analisar a política curricular em tela como produção discursiva e como luta pela fixação provisória de significados. As categorias que organizam a análise dos dados documentais são: demanda, antagonismo, articulação, hegemonia e significante vazio, estas categorias se originaram a partir de noções centrais que estruturam a Teoria do Discurso. Os resultados encontrados nos permitem afirmar que os discursos de integração hegemonizados nos textos curriculares não apresentam significados fixos e estáveis, mas vinculam uma multiplicidade de sentidos cambiantes e deslizantes, posto que construídos por meio de relações de diferenças e equivalências entre antigas e novas demandas que disputam espaço na política do nível médio. Pela impossibilidade da fixação de um sentido literal e transparente, capaz de abarcar ou cancelar todas as diferenças que atravessam a luta política, a negociação em torno da integração fez emergir um significante vazio, sob o qual deslizam sentidos ambíguos, contraditórios e flutuantes. Palavras-chave: Política Curricular; Ensino Médio; Integração.

Abstract: The paper focuses on the discourses of integration in Brazilian curricular policy for secondary education, from 1998 to 2012. The central objective is to understand the production of integration 
discourses as a hegemonic struggle for the meaning of the curriculum, evidencing the articulation process that enabled certain provisional and contingent meanings to be established in the curricular texts. Methodologically, the research is based on a qualitative approach and is characterized as a bibliographic and documentary review. Ernesto Laclau's Theory of Speech $(1987,2011,2013)$ and Stephen Ball's Continuing Cycle of Policies $(1992,1994)$ are the strategic contributions that support the research. This theoretical-methodological framework enabled us to analyze curricular policy as discursive production and as a struggle for the provisional establishment of meanings. The categories used to organize the data from the documentary analysis are: demand, antagonism, articulation, hegemony and empty signifier. These categories are derived from central notions that structure Discourse Theory. The results of this research showed that the hegemonized discourses of integration found in the curricular texts do not present fixed or stable meanings, but link a multiplicity of changing and shifting meanings, as they are constructed through relations of differences and equivalence between old and new demands that vie for space in the high school curriculum policy. Due to the impossibility of establishing a literal and transparent meaning that encompasses or cancels out all the differences that characterize the policy of struggle, a negotiation around integration led to the emergence of an empty signifier, under which ambiguous, contradictory and fluctuating meanings shift and change. Keywords: Curricular Policy; High School; Integration.

Resumen: El trabajo enfoca los discursos de integración en la política curricular brasileña para la escuela secundaria, en el período de 1998 a 2012. El objetivo central es comprender la producción de los discursos de integración como lucha hegemónica por la significación del currículo, evidenciando el proceso articulatorio que posibilitó la fijación de determinados sentidos provisionales y contingentes en los textos curriculares. Metodológicamente, la investigación se orienta en un enfoque cualitativo y se caracteriza como un estudio bibliográfico y documental. La Teoría del Discurso de Ernesto Laclau $(1987,2011,2013)$ y el Ciclo Continuo de Políticas de Stephen Ball $(1992,1994)$ son aportes estratégicos que subsidian la investigación. Este referencial teórico-metodológico nos posibilita analizar la política curricular como producción discursiva y como lucha por la fijación provisional de significados. Las categorías que organizan el análisis de los datos documentales son: demanda, antagonismo, articulación, hegemonía y significante vacío, estas categorías se originaron a partir de nociones centrales que estructuran la Teoría del Discurso. Los resultados encontrados nos permiten afirmar que los discursos de integración hegemonizados en los textos curriculares no presentan significados fijos y estables, pero vinculan una multiplicidad de sentidos cambiantes y deslizantes, puesto que construidos por medio de relaciones de diferencias y equivalencias entre antiguas y nuevas demandas que disputan espacio en la política para la escuela secundaria. Por la imposibilidad de la fijación de un sentido literal y transparente, capaz de abarcar o cancelar todas las diferencias que atraviesan la lucha política, la negociación en torno a la integración hizo emerger un significante vacío, bajo el cual deslizan sentidos ambiguos, contradictorios y flotantes. Palabras clave: Política Curricular; Escuela Secundaria; Integración.

\section{INTRODUÇÃO}

Desde a promulgação da Lei de Diretrizes e Bases da Educação (LDB), Lei 9.394/96, aprovada em dezembro de 1996, o ensino médio brasileiro tem sido alvo permanente de reformas que buscam adequar o currículo deste nível de ensino às diferentes demandas do mundo contemporâneo. Nos processos de reforma colocados em prática entre os anos de 
1998 a 2012, ora as exigências econômicas e de mercado, ora as demandas de inovação didático-metodológica, ora os objetivos de justiça social revezaram centralidade nas diretrizes curriculares produzidas pelo Ministério da Educação (MEC) e normatizadas pelo Conselho Nacional de Educação (CNE). O conjunto das orientações legais que subsidiaram as reformas em cenários políticos diferenciados tentaram imprimir na política concepções, objetivos e finalidades que entrecruzam visões pedagógicas pertencentes a diferentes domínios teóricos com interesses mais amplos inerentes aos projetos societários que disputam hegemonia na trama política brasileira.

Embora as reformas do período recortado tenham se fundamentado numa mesma lei educacional, estas seguiram orientações que revelam tanto uma relação de antagonismo quanto de negociação entre as demandas que vinham disputando hegemonia no contexto de produção dos textos curriculares oficiais. Os antagonismos e as disputas que perpassam a produção da política curricular demonstram que os textos legais são passíveis de diferentes leituras e entendimentos, podendo fomentar projetos e políticas dissonantes, ambíguas e contraditórias, dependendo das orientações assumidas pelas forças políticas que participam do jogo governamental, do poder de mobilização da sociedade para disputar suas demandas e do processo articulatório que se estabelece na produção de hegemonias sempre precárias e contingentes.

No transcurso das reformas do ensino médio colocadas em ação no decorrer dos mandatos do presidente Fernando Henrique Cardoso (1996-2002), do presidente Luís Inácio Lula da Silva (2003-2010) e da presidenta Dilma Rousseff (2011-2016), uma ideia que ganhou força e que motivou intensas disputas e negociações de sentidos é a ideia de integração curricular. O tema assumiu notável centralidade nos debates educacionais contemporâneos em função da importância atribuída à organização curricular como forma de adequar a educação às transformações econômicas, sociais e culturais dos nossos tempos.

Nas duas versões de Diretrizes Curriculares Nacionais para o Ensino Médio (DCNEM), produzidas entre 1998 a 2012, são apresentados discursos favoráveis à ideia de integração curricular. Ora tais discursos remetem a uma perspectiva mais metodológica de organização e desenvolvimento dos conteúdos curriculares, ora estão relacionados aos princípios filosóficos estruturantes da proposta de ensino médio integrado. A verdade é que a integração é uma discussão central nas políticas curriculares para o ensino médio nos últimos vinte anos, por isso os discursos que este significante articula podem ser compreendidos como uma luta incessante pela fixação de significados no currículo.

$\mathrm{Na}$ atual reforma do ensino médio, estabelecida inicialmente pela Medida Provisória $\mathrm{n}^{\circ}$. 746/2016, em setembro de 2016 e, agora, regulamentada pela Lei $n^{\circ} .13 .415 / 17^{1}$, a integração é um princípio que se encontra enfraquecido. Este enfraquecimento pode ser percebido não somente no que se refere à organização integrada dos conhecimentos das áreas curriculares que compõem a Base Nacional Curricular Comum (BNCC) ${ }^{2}$, mas, sobretudo, no que se refere à articulação entre educação básica e formação profissional por meio de um currículo unitário. Esta forma de integração já havia sido normatizada pelas DCNEM, em 2012, como uma alternativa para responder à demanda de inserção da juventude no mercado de trabalho, sem comprometimento e precarização da formação básica. No contexto de emergência da reforma 
autoritária e centralizadora decretada pelo governo ilegítimo de Michael Temer, não somente a integração entre conhecimentos gerais e específicos é confrontada, mas o próprio princípio de educação básica como formação ampla para a cidadania e para o aperfeiçoamento da pessoa humana é que vemos ameaçado.

Ao assumirmos como objeto de estudo os discursos de integração hegemonizados na política curricular brasileira para o ensino médio, no período de 1998 a 2012, a pesquisa procura responder a quatro questões fundamentais: Como e quando o significante integração emerge na política curricular brasileira para o ensino médio? Que sentidos de integração vêm sendo disputados nos textos curriculares oficiais? Por meio de que operações de equivalência e diferenças alguns sentidos têm alcançado hegemonia? Quais os antagonismos e as demandas que formam a cadeia articulatória dos discursos de integração? O objetivo central é compreender o processo de produção dos discursos de integração na política curricular do ensino médio como luta hegemônica pela significação do currículo, evidenciando as disputas e as negociações que possibilitaram a fixação de determinados sentidos provisórios e contingentes nos textos curriculares.

O presente trabalho é resultante da Tese de Doutorado ${ }^{3}$ realizada no âmbito Programa de Pós-Graduação em Educação da Universidade Federal do Pará (PPGED) e se caracteriza como uma pesquisa bibliográfica e documental, de enfoque qualitativo. Para a composição do estudo, reunimos diversas obras e documentos relativos à história e à política curricular do ensino médio brasileiro. Procuramos dar visibilidade a trabalhos de autores brasileiros que discutem o tema da integração curricular em diferentes perspectivas teórico-epistemológicas, desde aqueles mais ligados ao momento de emergência do discurso de integração no cenário político do ensino médio nos anos de 1980, como é o caso de Saviani (2003a; 2003b), passando pelos que aprofundam o tema no contexto da reforma dos anos de 1990 (LOPES, 2001, 2002a, 2002b, 2008; MACEDO, 2002; BERGER FILHO, 1999; RAMOS, 2006), até aqueles que implementam a discussão da integração no contexto do projeto de ensino médio integrado (RAMOS, 2004, 2007, 2011; MOURA, 2007; FRIGOTTO, 2012; CIAVATTA, 2012).

O corpus documental da pesquisa é constituído de documentos normativos e outros textos oficiais produzidos no âmbito do MEC e CNE no período recortado. Dentre os documentos que integram o estudo, constam as duas versões de DCNEM (Parecer CNE/CEB 15/98, Resolução CNE/CEB 03/1998, Parecer CNE/CEB 5/2011, Resolução CNE/CEB 02/2012); os Parâmetros Curriculares Nacionais para o Ensino Médio (1999); o Documento Base da Educação Profissional Técnica de Nível Médio Integrada ao Ensino Médio (2007); os textos para discussão preliminar das Diretrizes Curriculares Nacionais para a Educação Profissional Técnica de Nível Médio (2010) e para as Diretrizes Curriculares Nacionais para o Ensino Médio (2010), ambos de autoria do Grupo de Trabalho Interinstitucional criado no âmbito do MEC, com o objetivo de elaborar subsídios ao debate sobre os pareceres e as resoluções referentes às respectivas diretrizes.

A Teoria do Discurso de Ernesto Laclau e Chantal Mouffe (1987); Ernesto Laclau (2011, 2013) e o Ciclo Contínuo de Políticas de Stephen Ball (1994); Stephen Ball e colaboradores (1992) são aportes estratégicos que subsidiam a investigação. Estes referenciais teórico- 
metodológicos nos possibilitam analisar a política curricular em tela como produção discursiva e como luta pela fixação provisória e contingente de significados. Demanda, antagonismo, articulação, hegemonia e significante vazio são as categorias que orientaram a análise dos dados. Tais categorias foram construídas com base nas noções centrais da Teoria do Discurso e tentam traduzir as negociações, as disputas e as articulações que atravessam a produção e a hegemonização dos discursos de integração nos documentos analisados. Os resultados encontrados nos permitem afirmar que os discursos que alcançaram hegemonia nos textos curriculares não apresentam significados fixos e estáveis, mas vinculam uma multiplicidade de sentidos cambiantes e deslizantes, posto que construídos por meio de relações de diferenças e equivalências entre antigas e novas demandas que disputam espaço na política do nível médio. Pela impossibilidade da fixação de um sentido literal e transparente, capaz de abarcar ou cancelar todas as diferenças que atravessam a luta política, a negociação em torno da integração fez emergir um significante vazio, sob o qual deslizam sentidos ambíguos, contraditórios e flutuantes.

\section{A EMERGÊNCIA DO DISCURSO DE INTEGRAÇÃO NA POLÍTICA PARA O ENSINO MÉDIO E OS SENTIDOS PRIVILEGIADOS NOS ANOS DE 1990}

A emergência do discurso de integração na história do ensino médio brasileiro se situa no contexto dos anos de 1980, no movimento de mobilização pela construção de um novo projeto de LDB que se sucedeu à promulgação da Constituição Federal de 1998. A partir deste momento, o debate em torno do significado do ensino médio ganhou nova relevância e tomou novos rumos, em consonância com clima de abertura política fomentado no processo de redemocratização. Momento em que os estudos críticos sobre a dimensão política da educação escolar ganham relevo. Neste período, as teorias críticas passaram exercer grande influência no pensamento educacional brasileiro, especialmente no âmbito do nível médio. A partir de outras bases teórico-epistemológicas, alguns segmentos críticos, sobretudo aqueles ligados à comunidade epistêmica Trabalho e Educação ${ }^{4}$, procuram confrontar a concepção dualista de educação que atravessa a constituição histórica deste nível de ensino e que se tornou estrutural com as primeiras leis orgânicas da educação secundária nos anos de 1940.

A partir deste momento, o discurso de integração foi se desenvolvendo e ganhando centralidade no âmbito da política educacional brasileira, passando a assumir significados diversos conforme os interesses e as demandas que vêm participando do jogo político pelo estabelecimento de diretrizes para o currículo da escola média. Defendemos que foi no projeto original de LDB (Projeto de Lei $n^{\circ}$. 1.258/88), apresentado pelo Deputado Federal Otávio Elísio em 1988, que apareceu pela primeira no cenário político brasileiro do ensino médio o discurso de integração numa perspectiva crítica e progressista. Neste momento, o sentido atribuído à integração era de integrar educação básica à formação profissional em outras bases que não a de adaptação da educação escolar às demandas do mundo produtivo. Os defensores da 
integração no âmbito deste projeto criticavam severamente a maneira como esta relação foi preconizada pela política de profissionalização da Lei 5.692/71. Assim, a integração emerge nos anos de1980 sob o signo da politecnia.

Na perspectiva de Saviani (2003a, 2003b), o projeto educativo da politecnia visava enfrentar a velha problemática do dualismo e da ambiguidade do ensino médio a favor de uma educação crítica e integradora. Era um projeto que afirmava a necessária vinculação entre educação básica e prática social e assumia o trabalho como um princípio educativo fundamental. O ensino médio concebido na perspectiva de uma educação politécnica deveria se desenvolver a partir da compreensão de que o conceito e o fato do trabalho são elementos organizadores do ensino em geral, assim como do próprio currículo.

Sustentamos que o discurso de integração, na perspectiva teórica da politecnia, foi aos poucos negociando seus sentidos originais com outras demandas que participaram do processo articulatório no desdobramento do processo de elaboração e aprovação da LDB.

As Diretrizes Curriculares Nacionais para o Ensino Médio (DCNEM) e os Parâmetros Curriculares Nacionais para o Ensino Médio (PCNEM), estabelecidos em decorrência da LDB sancionada no ano de 1996, foram dispositivos de prescrição curricular que advogaram a favor da integração como um princípio ideal de organização do currículo. Entretanto, em sintonia com os modelos de reformas educativas desenvolvidas em países centrais do mundo capitalista, tomadas como exemplares para a implementação de reformas nos sistemas de ensino de países com baixo índice de desenvolvimento econômico, a reforma brasileira se constrói com base em princípios axiológicos e pedagógicos que traduzem a identificação da política curricular brasileira com as recomendações emanadas das agências internacionais.

A proposta de uma educação a ser desenvolvida ao longo da vida estava fortemente relacionada à ideia de inovação daquele que chamou de o novo ensino médio brasileiro em oposição à ideia de um currículo enciclopédico, fragmentado, descontextualizado e desinteressante, responsável pelo insucesso dos alunos e pela defasagem entre o conhecimento escolar e as demandas sociais e produtivas dos novos tempos (BRASIL, 1998).

Permitindo-nos uma breve digressão, identificamos que este discurso retorna com força total na reforma atual do governo de Michel Temer, inclusive, as alterações propostas pela Lei 13.415/17 são, também, justificadas pelo mesmo discurso retórico sobre a urgência da escola em renovar o seu currículo como forma de corresponder aos anseios dos jovens, que não se identificam com um modelo de ensino sobrecarregado de conteúdos sem aplicabilidade e que desejam flexibilizar as suas trajetórias escolares por meio de itinerários que se aproximem mais das suas expectativas de vida. Este projeto é outra vez denominado de o novo ensino médio brasileiro. Tal semelhança retórica nos leva a inferir que entre o projeto educativo de Fernando Henrique Cardoso e o projeto de Michel Temer há mais equivalências e continuidades do que se pode supor.

Competências, interdisciplinaridade, contextualização são, portanto, três sentidos privilegiados do discurso de integração defendidos na reforma do ensino médio nos anos de 1990. Definidos como princípios metodológicos complementares no processo de organização do currículo, esses significantes foram apresentados com uma aparente unidade 
teórico-epistemológica. No entanto, conforme já discutiram Lopes (2001, 2002a, 2002b, 2008) e Macedo (2002), tais sentidos foram construídos a partir da hibridização de discursos pedagógicos e curriculares pertencentes a diferentes domínios teóricos e representam um esforço de compatibilizar demandas não somente diferentes, mas divergentes e até mesmo contraditórias colocadas por grupos e sujeitos envolvidos na luta hegemônica pela significação do currículo naquele contexto.

Um argumento recorrentemente utilizado nas DCNEM para justificar a organização do currículo com base no desenvolvimento de competências eram as mudanças ocorridas no mundo produtivo e as formas de conviver do mundo contemporâneo que passaram a exigir um novo perfil de pessoa humana, impossível de ser alçando por meio de um tipo de ensino "enciclopédico e academicista dos currículos de ensino médio tradicionais". Por isso, uma das novas funções reclamadas para o ensino é o desenvolvimento da capacidade do educando de aprender ao longo da vida "com destaque para o aperfeiçoamento do uso das linguagens como meios de constituição dos conhecimentos, da compreensão e da formação de atitudes e valores" (BRASIL, 1998, p. 27).

Para isso, o mesmo documento prossegue afirmando que a organização curricular do ensino médio deveria ser orientada por uma "visão orgânica do conhecimento afinada com as mutações surpreendentes que o acesso à informação está causando no modo de abordar, analisar, explicar e prever a realidade" (BRASIL, 1998, p. 27). Esses argumentos estavam afinados com as recomendações das agências internacionais para a reformulação do currículo da escola média que visavam desenvolver no educando os conhecimentos, os valores e as atitudes necessárias à sua inserção no mundo do trabalho e a sua adaptação às novas configurações da vida produtiva e das formas de convivência societária em nível planetário. Especialmente as recomendações da UNESCO contidas no Relatório da Reunião Internacional sobre Educação para o Século XXI (DELORS, 1998) traziam as orientações das mudanças que deveriam ser operadas na escolarização e no currículo na passagem do século XX para o século XXI. Segundo a UNESCO, os quatro pilares da educação para o novo século se traduzem nas capacidades de aprender a conhecer; aprender a fazer; aprender a conviver; aprender a ser. Os discursos subjacentes a estas quatro grandes necessidades de aprendizagem foram recontextualizados pelas DCNEM na forma dos princípios axiológicos do novo ensino médio brasileiro, objetivandose na estética da sensibilidade, na política da igualdade e na ética da identidade. O conjunto desses princípios pressupunha a construção de competências básicas de caráter cognitivo, técnico, social e pessoal que são valorizadas pelas novas formas de produção pós-industrial. Dessa forma, enquanto que no modelo taylorista-fordista a especialização do saber e do fazer é a base que informa a educação escolar e a qualificação profissional; no novo paradigma pósindustrial é necessário integrar as dimensões do conhecimento, da técnica e dos valores num projeto mais ambicioso de desenvolvimento da pessoa humana.

É exatamente este comprometimento com os preceitos econômicos e de mercado e com a submissão da educação ao mundo produtivo que demarca o antagonismo do projeto educativo da reforma dos anos de 1990 em relação ao ideal de emancipação e justiça social que caracterizava o projeto educacional dos anos de 1980. Como isso, não pretendemos afirmar 
a existência de uma polaridade binária entre justiça e injustiça, dominação e emancipação entre os mesmos projetos, defendemos, com base em Ball (1994) e em Laclau (2013), que a produção da política é algo bem mais complexo e que as articulações entre demandas diferentes e antagônicas não permitem a plena universalização de sentidos puros, sem que haja uma negociação desses sentidos entre os sujeitos e os grupos que participam das disputas pelo seu estabelecimento.

Nos PCNEM, a ideia de competência como adaptação às exigências do mundo produtivo também foi utilizada para justificar as mudanças requeridas à educação no contexto da nova sociedade tecnológica em que o conhecimento assume centralidade nos processos de produção e de organização da vida social. Segundo este paradigma educacional, a educação precisaria responder ao imperativo de desenvolver competências nos educandos para construir e mobilizar conhecimentos que pudessem ser empregados na solução de problemas colocados pelo mundo do trabalho, pela prática cotidiana e pela convivência social. Portanto, no lugar de uma escola que pretendesse formar por meio da "imposição de modelos, de exercícios de memorização, da fragmentação do conhecimento, da ignorância dos instrumentos mais avançados de acesso ao conhecimento e da comunicação" (BRASIL, 1999, p. 12), outra escola precisaria surgir, mais conectada com as mudanças sociais em curso e com as necessidades de aprendizagem requeridas pela nova sociedade do conhecimento.

Para se alcançar a consecução de tais objetivos, os documentos orientavam que a organização do currículo deveria se estruturar não mais com base nos conhecimentos propedêuticos pertencentes aos distintos campos disciplinares que tradicionalmente têm composto o repertório de ensino da escola secundária, mas sim nas competências básicas e nas habilidades que deveriam ser desenvolvidas a partir da diversidade e da complexidade dos conhecimentos pertencentes às três grandes áreas integrantes da base nacional comum curricular do ensino médio no contexto daquelas DCNEM: Linguagens, Códigos e suas Tecnologias(Língua Portuguesa, Língua EstrangeiraModerna, EducaçãoFísica, ArteeInformática); Ciências da Natureza, Matemática e suas Tecnologias (Química, Física, Biologia e Matemática); Ciências Humanas e suas Tecnologias (História, Geografia, Sociologia, Antropologia \& Política e Filosofia). Cada uma destas áreas passou a ser constituída pelo agrupamento de disciplinas consideradas potenciais, mas não obrigatórias para o planejamento e a implementação do currículo, embora que, contraditoriamente, as competências e as habilidades nos PCNEM sejam listadas com referência às disciplinas que compõem cada área.

A despeito das competências terem sido defendidas como o principal eixo de estruturação do currículo, o que percebemos é que a garantia da efetividade desse princípio não residia tanto na diferenciação da organização do currículo com base na disciplina ou na competência, mas sim no tipo de abordagem dos conhecimentos que, conforme previsto nas DCNEM e nos PCNEM, deveria se desenvolver na perspectiva da interdisciplinaridade e da contextualização como princípios didático-pedagógicos complementares à noção de competência e como tecnologias enriquecedoras da prática pedagógica.

A compatibilidade desse sentido de competências com a lógica disciplinar que permaneceu informando o currículo, a despeito da centralidade colocada na primeira, se mostrou problemática. 
Pois, se a competência estava sendo entendida como a capacidade de ação específica e concreta, esta fugia ao limite das disciplinas científicas ou escolares (MACEDO, 2002, p.123). Isso se traduz numa tensão entre competência e disciplinarização no interior dos documentos daquele período, essa tensão se fazia presente, muitas vezes, num mesmo documento.

Nesse sentido, Macedo (2002, p. 138) defende que o discurso de competências na política curricular dos anos de 1990 precisa ser compreendido como "um processo híbrido para o qual conflui uma multiplicidade de diferentes tendências e orientações teórico-metodológicas, nem sempre formando um todo homogêneo".

Essa perspectiva também é compartilhada por Lopes (2002a, 2002b, 2008), que observa a mesma tendência de hibridização na construção dos discursos de interdisciplinaridade e contextualização, também, associados à noção de currículo por competências. Segundo Lopes (2008), essa estratégia é utilizada para compatibilizar demandas e visões diferentes acerca do currículo, ocasionadas não somente pelas diferenças de perspectivas epistemologias que foram mobilizadas na construção de tais discursos, mas, também, para alcançar legitimidade junto aos diferentes grupos que participantes das disputas e das negociações em torno do currículo, os quais buscavam controlar os significados da política. Pois as ideias de interdisciplinaridade e contextualização, por serem identificadas pelas comunidades educacionais pela sua filiação às teorizações progressivista e crítica de currículo, se mostravam mais palatáveis aos professores e a outros sujeitos situados em diferentes campos disciplinares, chegando mesmo a serem desejáveis como tecnologias de desenvolvimento de transposição didática do currículo.

A política curricular brasileira para o ensino médio nos anos de 1990 colocou um foco bastante acentuado na integração curricular associada à ideia de inovação e de mudança. Da mesma maneira, nessas políticas se manteve um discurso de conciliação entre integração e disciplinarização por via de um enfoque que procurou valorizar a interdisciplinaridade e a contextualização. Por meio de tais discursos conciliatórios, a integração não chegou a abalar a força da organização curricular disciplinar, tampouco conseguiu alterar substancialmente os desenhos curriculares que, perceptivelmente, continuaram tendo por base as disciplinas acadêmicas de referência para o processo de seleção dos saberes e dos conhecimentos escolares, sem contar que o processo avaliativo da educação básica também permaneceu estruturado numa lógica disciplinar de organização e desenvolvimento do currículo.

O antagonismo com a significação de integração compreendida como competências para competitividade e empregabilidade e de contextualização e interdisciplinaridade como elementos meramente pedagógicos de organização do currículo serão frontalmente confrontados pelos sujeitos e grupos críticos que retornam à trama a partir de 2003 e se realinham no contexto de produção da política curricular para disputar outras significações para o currículo do nível médio, cujo foco no significante integração é uma das marcas mais determinantes. Isso não significa que a lógica prevalente na reforma dos anos de 1990 tenha se retirado totalmente de cena, mas significa que, a partir deste momento, o campo de disputa vai ser atravessado por sentidos mais amplos e críticos de integração. 


\section{A POLÍTICA CURRICULAR NOS ANOS DE 2003 A 2012 E A DISPUTA POR OUTROS SENTIDOS DE INTEGRAÇÃO}

A partir dos anos 2003, sobretudo a partir da influência da comunidade epistêmica Trabalho e Educação, que passou a ganhar um significativo espaço na produção da política do ensino médio no contexto dos governos de Luís Inácio Lula da Silva e de Dilma Rousseff, ambos do Partido dos Trabalhadores (PT), outra reforma do ensino médio foi fomentada. Esta reforma seguiu uma orientação político-filosófica de viés crítico consonante ao posicionamento teórico daquela comunidade epistêmica. Os ideais de integração de orientação marxista e gramsciana foram propagados como capazes de desafiar as orientações curriculares hegemonizadas pela reforma dos anos de 1990 e recolocar o debate deste nível de ensino em termos de uma luta político-social mais ampla, pautada nos objetivos de justiça e emancipação social.

Localizamos que, neste momento, o projeto de ensino médio buscou recolocar a concepção de educação básica e de formação profissional de caráter unitário, omnilateral e politécnico, conforme havia sido demarcado no projeto original da LDB disputado nos de 1980. Assim, surgiu como resultado de um amplo processo de mobilização e disputa no âmbito do MEC e do CNE o projeto de ensino médio integrado, o qual estabeleceu as principais bases para a proposta de integração que lutou para se hegemonizar nos textos políticos deste novo período de reforma (2003-2012).

As análises que realizamos a partir do corpus documental da pesquisa nos possibilitam afirmar que o projeto de ensino médio integrado construído sob a influência da comunidade epistêmica Trabalho e Educação procurou retomar o ideário de integração na perspectiva da politecnia. Defendemos que a disputa por um novo sentido de integração no projeto curricular para o ensino médio em período mais recente tendeu a se distanciar de uma base teórica informada pela psicologia condutivista e cognitivista, pelas teorias curriculares de domínio eficientista e técnico-instrumental, mescladas a discursos pedagógicos progressivistas e críticos (MACEDO, 2002), predominantes nos discursos de integração dos anos de 1990 e passou a se estruturar numa base teórica político-sociológica, informada pelas teorias marxista e gramsciana.

Desta maneira, no contexto do jogo político ascendente, percebemos a ocorrência do deslocamento de um sentido de integração mais restrito ao debate didático-pedagógico, calcado na hibridização de discursos de diferentes teorias pedagógicas e curriculares, para um sentido mais político e filosófico, que procura definir uma identidade e uma função social para o ensino médio a partir de princípios que desafiam os objetivos de submissão da educação escolar ao mundo produtivo e centram os seus objetivos em perspectivas críticas de educação e trabalho, o que contribui para definir, em boa medida, os sentidos precários e contingentes que a integração assumiu nas novas DCNEM, homologadas em 2012.

As ideias de integração presentes no projeto do ensino médio integrado, tal como formulado pelo Grupo de Trabalho (GT) responsável pela proposição do documento preliminar à discussão do Parecer CNE/CEB n 05/2011, que define novas diretrizes para o nível médio, mobilizam três noções primordiais da teoria marxista e gramsciana: a concepção de educação 
omnilateral e politécnica, de escola unitária e do trabalho como princípio educativo. As DCNEM aprovadas (Resolução CEB/CNE n 02/2012) refletiram as negociações ocorridas entre a proposta do GT, o MEC e o CNE. No texto final do Parecer que consubstancia as novas diretrizes, é possível perceber as mesclas decorrentes das articulações entre concepções, objetivos e demandas colocadas em pauta pelos sujeitos e grupos atuantes no contexto de produção daquele texto.

Identificamos que os sentidos de integração que foram hegemonizados pelas DCNEM podem ser traduzidos em três princípios integradores estruturantes do projeto de ensino médio integrado: o primeiro é o da integração entre educação básica e educação profissional; o segundo é o da formação humana integral pelo eixo do trabalho, ciência, tecnologia e cultura; e o terceiro é a integração na perspectiva da interdisciplinaridade e da totalidade como princípio filosófico e metodológico de organização do currículo.

Sustentamos que estes sentidos conseguiram se hegemonizar nas DCNEM por meio de diversas articulações discursivas que ora reafirmam os princípios de integração originalmente desenvolvidos pela teoria marxista e gramsciana, assim como pelas suas interpretações por autores brasileiros, ora apontam para o esvaziamento desses sentidos e para construções ambíguas e ambivalentes que produzem sentidos flutuantes para este significante.

Diante da pluralidade das demandas que constituem a cadeia discursiva do discurso de integração, argumentamos que é importante compreender o jogo de linguagem presente no texto político oficial, pois tal jogo tem a intenção produzir um discurso por meio de equivalências entre propostas antagônicas e que muitas vezes parecem mesmo irreconciliáveis. Por isso, sustentamos o argumento de que a fixação de um sentido literal para o significante integração no interior do texto político oficial é um horizonte impossível de ser alcançado, pois nenhuma das demandas que formam a cadeia de equivalências do discurso que disputou hegemonia no texto das DCNEM de 2012 consegue representar plenamente as demandas nas suas particularidades. Surge daí uma hegemonia precária, devido à necessidade de significar de alguma forma e de dar nome à identidade que emerge da prática articulatória, uma prática que não obedece a nenhum fundamento ou estrutura determinada a priori.

Neste sentido, defendemos que, entre os anos de 2003 a 2012, os discursos de integração passaram a articular outros sentidos diferentes daqueles hegemonizados nos anos de 1990. A fronteira antagônica da integração, antes simbolizada pela disciplinarização do currículo, sofre alguns deslocamentos em função da não fixidez da relação de antagonismo que configurou este discurso no período anterior. Neste novo contexto, o outro antagônico do discurso de integração não é somente a organização disciplinar fragmentada e descontextualizada, mas a desarticulação entre educação básica e educação profissional (dualismo), a parcialidade da formação voltada para o desenvolvimento de competências para o mercado e para o trabalho e a dissociação entre conhecimentos gerais e conhecimentos específicos na organização do currículo. No entanto, não há nenhuma oposição severa à organização disciplinar, pois esta é defendida como um tipo de organização que pode conviver sem conflitos com outras perspectivas de organização integrada como a interdisciplinaridade e a transversalidade. 


\section{Sentidos hegemonizados nAs DCNEM de 2012 e PROduçÃo dA INTEGRAÇÃO COMO UM SIGNIFICANTE VAZIO}

A superação da dicotomia entre educação básica e educação profissional é um dos sentidos centrais de integração disputados pelos propositores do projeto de ensino médio integrado que vinha sendo costurado desde o início do Governo Lula, no contexto das mobilizações para a revogação do Decreto 2.208/97 e aprovação do Decreto 5.154/2004. Essa discussão foi pautada em diversos eventos e documentos oficiais ${ }^{5}$ organizados sob a coordenação do MEC com o objetivo de estabelecer e difundir os princípios e as concepções fundamentais do projeto, assim como de orientar a sua construção metodológica.

A integração compreendida pelo viés da conjugação entre formação geral e formação específica, no mesmo curso, tem origem nos pressupostos de educação ominilateral, unitária e politécnica preconizada pelos discursos marxistas e gramscianos de educação. Nesses registros, todos os estudantes deveriam ter acesso, no período que corresponde à escola básica, a uma educação de caráter geral de base unitária que conjugue conhecimentos e dimensões consideradas fundamentais para uma formação humana integral. A escolha de uma formação profissional específica só aconteceria após a conclusão da educação básica em curso universitário.

Entretanto, considerando as condições materiais da juventude brasileira, em que grande parte dos jovens é levada a buscar a inserção no mercado de trabalho antes mesmo de completar os 18 anos de idade, visando complementar a renda familiar ou garantir seu autossustento. Os defensores desta concepção julgam impossível pensar na implementação de um modelo de ensino politécnico na educação básica em toda a plenitude que a concepção original sugere, em virtude da extrema desigualdade socioeconômica persistente na nossa "rebelde realidade social" (SAVIANI, 2003a; MOURA, 2007; RAMOS, 2007; FRIGOTTO et al, 2012).

Esta flexibilização na noção de educação unitária e politécnica já indica uma primeira operação de articulação que o discurso de integração realiza no contexto das novas DCNEM. A formação profissional, com vistas à inserção no mundo do trabalho, é uma demanda que impede que a integração, concebida pelo viés da politecnia, se concretize de forma total. A ideia de unitariedade tal como concebida por Gramsci é incomensurável com a complexidade que configura a dinâmica do social e com significação de diferentes segmentos sociais a respeito das finalidades da escola média no contexto brasileiro contemporâneo.

A impossibilidade da plena realização deste sentido de integração no estágio atual perpassa o discurso de vários autores brasileiros que se propuseram a delinear o projeto de ensino médio integrado à educação profissional a partir de uma base curricular unitária. Como solução transitória, o projeto de ensino médio integrado vinha sendo pensado com o objetivo de garantir a integralidade da educação básica em todos os aspectos do desenvolvimento humano: científico, tecnológico e cultural, somada aos objetivos de formação profissional. Com isso, se pretendia configurar uma nova identidade para o ensino médio com vistas à superação da dualidade estrutural em que a formação acadêmica é pensada para uma minoria 
e a formação instrumental para a maioria que não pode se dar o "luxo" de apenas estudar. O ensino médio integrado poderia representar, então, uma espécie de "travessia para uma nova realidade" (FRIGOTTO et al., 2012).

As questões que marcaram as disputas e os embates em torno do ensino médio e da educação profissional ao longo dos anos 2000 não se mostraram menos polêmicas no contexto das DCNEM de 2012. O impasse sobre a definição da identidade do ensino médio e sobre as formas de articulação entre educação básica e profissional que vinha se arrastando desde a aprovação do Decreto 5.154/2004 permanece como uma questão de difícil resolução.

As DCNEM afirmavam que a profissionalização é uma das formas possíveis de diversificação do ensino médio, visando atender aos jovens que têm o acesso ao trabalho como uma perspectiva de vida mais imediata. Essa oferta poderia ocorrer de forma integrada, concomitante ou subsequente à educação básica. Importa que configurasse um modelo unitário, ainda que assume formas diversas e contextualizadas, de acordo com as características dos sujeitos. Se a formação profissional é

[...] uma imposição da realidade destes jovens, representando importante alternativa de organização, não pode se constituir em modelo hegemônico ou única vertente para o Ensino Médio, pois ela é uma opção para os que, por uma ou outra razão, a desejarem ou necessitarem. (BRASIL, 2011, p. 30).

A despeito de tal afirmativa, paradoxalmente, se segue afirmando nas DCNEM que é preciso que a escola pública construa propostas pedagógicas sobre uma base unitária para todos, mas que possibilite situações de aprendizagem variadas, com ou sem profissionalização.

A questão da garantia de universalização da educação básica como condição primeira para uma formação profissional não restrita à ideia de treinamento ou de preparação para o emprego era o que de fato vinha sendo colocado em pauta pela comunidade epistêmica Trabalho e Educação no processo de produção da política do ensino médio. $O$ debate não estava circunscrito simplesmente à questão alternativa de o ensino médio incluir ou não a dimensão da profissionalização, mas o ponto principal que se procurava atacar é em que condições e com que finalidades essa formação vinha se processando e qual a sua implicação para a qualidade da formação e da vida das pessoas.

Com base nas questões destacadas, defendemos que a discussão sobre integração, na perspectiva em que vinha sendo construída pelos sujeitos que defendiam o projeto de ensino médio integrado de base unitária e politécnica, tomou, no contexto daquelas diretrizes, uma configuração diferenciada, ocorrendo um esvaziamento dos sentidos originais da demanda de integração concebida como um processo que articula formação geral e específica sob princípios filosóficos, políticos e pedagógicos únicos. O que ocorreu foi uma tentativa de fixação de sentidos ambíguos em que integração foi sendo significada como uma das formas possíveis de oferta do nível médio e que poderia conviver com outras formas, sem prejuízo da unitariedade do projeto de ensino. Desta maneira, a questão da dualidade permanece como uma marca do ensino médio, que mais uma vez não conseguiu ser enfrentada com toda a radicalidade almejada. Parafraseando Ramos (apud MOURA, 2012), pode-se dizer que se conseguiu garantir a forma integrada, como forma, mas esta foi sendo cada vez mais deformada.

A proposta de formação humana integral articulada pelo eixo do trabalho, ciência e tecnologia é um segundo sentido de integração que perpassa o projeto de ensino médio 
integrado que deu base às DCNEM. Este sentido guarda estreita relação com o primeiro na medida em que a superação do dualismo entre formação geral e formação específica pressupõe que a educação se desenvolva de forma integrada a partir de uma base unitária formada por conhecimentos "humanísticos", na perspectiva em que Gramsci compreende o humanismo, que se relacionam com os modos produtivos da existência humana por meio do trabalho compreendido como atividade criativa de mediação entre homem-natureza, como forma de produção da existência humana, mediada pela ciência e pela cultura. Desta maneira, de acordo com os fundamentos do projeto de ensino integrado, uma formação de base unitária e politécnica compreende o trabalho como princípio educativo e a ciência, a tecnologia e a cultura como elementos essenciais para a compreensão dos fundamentos que estruturam os processos produtivos na sociedade contemporânea (RAMOS, 2004, 2007, 2011; FRIGOTTO et al., 2012; CIAVATTA, 2012).

O princípio de formação integral absorvido pelas DCNEM também remonta o conceito de educação omnilateral, tributário do ideário socialista de educação, que entende a educação como um processo integral de formação e compreende as dimensões física, mental, cultural, política, científica e tecnológica. Nessas definições de formação integral, estão implicadas compreensões sobre trabalho, ciência, tecnologia que se tornam conceitos centrais de constituição do eixo privilegiado de orientação para a organização da proposta curricular do ensino médio integrado. Coerentemente com a base epistemológica que sustenta tal proposta, o trabalho é entendido como mediação primeira do processo de produção e de objetivação da existência humana.

Os autores da proposta de ensino médio integrado afirmam que a relação entre educação básica e trabalho no âmbito das políticas educacionais brasileiras tem se pautado muito mais pelo entendimento de trabalho como valor de troca e como sinônimo de emprego ou como atividade empreendedora. Daí sempre ser enfatizada a finalidade de formar para o trabalho no sentido de formar para a laboridade.

O sentido de integração aqui caracterizado foi incorporado pelo texto das DCNEM de forma mais próxima às ideais dos autores do projeto de ensino integrado. Estes princípios também foram assumidos como base unitária para estruturação do currículo de cursos em que a formação profissional ocorresse de forma concomitante ou subsequente ao ensino médio, ou seja, de cursos em que a educação profissional estivesse conceitualmente apartada da educação básica, constituindo-se como um apêndice ou como uma formação independente desta.

O terceiro sentido de integração disputado pelo projeto de ensino médio integrado faz emergir a célebre discussão da organização curricular. Os dois sentidos de integração tratados anteriormente são de ordem mais sociológica, filosófica, ética e política, visto que procuram definir finalidades, princípios e concepções sobre o ensino médio sem adentrar numa discussão propriamente curricular. Na discussão deste terceiro sentido já se pode perceber uma maior aproximação com perspectivas de integração produzidas pela teorização curricular

A interdisciplinaridade como possibilidade para a construção do currículo integrado é enfocada com base em duas referências sobre o tema: a desenvolvida por Santomé (1998); e a desenvolvida por Bernstein (1981). Ao propor a organização integrada do currículo, Ramos 
$(2007,2011)$ declara que a nova proposta de integração incorpora elementos das teorizações de Santomé e Bernstein sobre interdisciplinaridade, mas vai além delas, pois tem mais clara as finalidades da formação dos sujeitos que se traduz em possibilitar a compreensão da realidade para além de sua aparência. Desta maneira, os conteúdos de ensino não teriam fim em si e nem se limitariam a insumos para o desenvolvimento de competências. Os conteúdos se constituiriam em conceitos e teorias que traduzem a síntese da apropriação histórica da realidade material e social pelo homem.

O conceito de totalidade é informado pela concepção de Kosik (apud RAMOS 2007, p. 17), para quem totalidade significa "um todo estruturado e dialético, do qual ou no qual um fato ou um conjunto de fatos pode ser racionalmente compreendido pela determinação das relações que o constituem". Cada fato ou conjunto de fatos reflete a realidade com maior ou menor riqueza. A possibilidade de se conhecer a totalidade a partir das partes é dada pela possibilidade de se identificar os fatos que esclareçam sobre a essência do real. Por outro lado, é necessário que se faça a distinção entre o que é essencial e acessório, assim como o sentido objetivo dos fatos (BRASIL, 2011).

Nesta visão, o currículo integrado "organiza o conhecimento e desenvolve o processo de ensino aprendizagem de forma que os conceitos sejam apreendidos como sistema de relações de uma totalidade concreta que se pretende explicar/compreender." (RAMOS, 2007, pp. 17-18).

A relação entre partes e totalidade no contexto de uma organização curricular que compreende componentes curriculares considerados básicos para uma formação integral e politécnica e outros, de caráter mais específicos, relacionados a determinados campos de profissionalização, aparece como uma necessidade, como um princípio organizador do currículo e como um método de ensino-aprendizagem. Assim, pressupõe-se que os conceitos científicos que constituem as várias disciplinas deveriam ser relacionados à luz de problemas concretos que se busca compreender. Entretanto, há de se ressaltar que isso não compromete a identidade epistemológica das diversas disciplinas.

Ramos (2011) argumenta que, se as disciplinas escolares, como "acervos de conteúdos de ensino", permanecerem isoladas entre si e desprendidas da realidade concreta, não há como se processar a compreensão do real. Com isso, qualquer tentativa de se realizar a interdisciplinaridade será falha e não passará de estratégia de relação mecânica entre fato e conceitos. Nesse sentido, Ramos tece a crítica tanto às perspectivas instrumentais e tecnicistas de currículo, quanto à concepção de integração por via da noção de competências. A autora sustenta que a proposta de integração que lhe parece mais pertinente ao ensino médio integrado é aquela que tem como base a compreensão do real como totalidade histórica e dialética, por isso não será a pedagogia das competências capaz de converter o currículo em um ensino integral. Visto que os conhecimentos não podem ser entendidos na sua utilidade prática, mas precisam ser compreendidos na sua historicidade e nas relações que estabelecem com os fatos, nesse sentido, também, não prescindem de um posicionamento epistemológico e crítico frente a essa mesma realidade.

No contexto daquelas DCNEM, as concepções sobre integração curricular, conforme discutidas por Ramos (2007, 2011), foram em grande parte incorporadas pelo Parecer CEB/ 
CNE n 05/2011, no item denominado Organização Curricular do Ensino Médio. Entretanto, neste mesmo item, os pareceristas do CNE chamam a atenção para o fato de que as estratégias e as metodologias de integração são práticas bastante desafiadoras na organização curricular, na medida em que exigem uma articulação e um diálogo entre os conhecimentos, rompendo com a forma fragmentada como historicamente tem sido organizado o currículo do ensino médio. As DCNEM procuram justificar a impossibilidade de uma implementação plena da integração curricular nos termos antes colocados em função da:

[...] necessidade do aprofundamento dos conceitos inerentes às disciplinas escolares, já que cada uma se caracteriza por ter objeto próprio de estudo e método específico de abordagem. Dessa maneira, tem se revelado praticamente difícil desenvolver propostas globalizadoras que abranjam os conceitos e especificidades de todas as disciplinas curriculares. (BRASIL, 2011, p. 43)

Assim, apresentamos como saída para o impasse a possibilidade da coexistência de duas formas de organização curricular: uma disciplinar e outra interdisciplinar, que busca o enfraquecimento das barreiras disciplinares sem, no entanto, abrir mão das especificidades dos conceitos e dos conhecimentos que as integram. A coexistência entre essas duas formas de organização curricular, que por princípios epistemológicos são adversas, conforma, no contexto das DCNEM, o que a mesma denomina de "metodologia mista de organização do currículo". De outra forma, também resgatamos nessas DCNEM o conceito de interdisciplinaridade definido nas Diretrizes Curriculares Nacionais Gerais para a Educação Básica (Parecer CNE/CEB n 7/2010), em que a interdisciplinaridade é apresentada como um conceito equivalente e complementar da noção de transversalidade, forma que assumiu a integração nas Diretrizes Curriculares Nacionais para o Ensino Fundamental nos anos de 1990. Sobre o conceito de interdisciplinaridade, aquelas diretrizes assim se referem:

A interdisciplinaridade pressupõe a transferência de métodos de uma disciplina para outra. Ultrapassa-as, mas sua finalidade inscreve-se no estudo disciplinar. Pela abordagem interdisciplinar ocorre a transversalidade do conhecimento constitutivo de diferentes disciplinas, por meio da ação didático-pedagógica mediada pela pedagogia dos projetos temáticos. (BRASIL, 2011, p. 44)

Enquanto que a transversalidade é definida nos seguintes termos:

A transversalidade é entendida como forma de organizar o trabalho didático pedagógico em que temas, eixos temáticos são integrados às disciplinas, às áreas ditas convencionais de forma a estarem presentes em todas elas. (BRASIL, 2011, p. 44)

Desta maneira, acaba-se também por ressuscitar, indiretamente, a pedagogia de projetos que é uma perspectiva de integração completamente distante da proposta de interdisciplinaridade e totalidade do projeto de ensino médio integrado discutido pela comunidade epistêmica Trabalho e Educação. A interdisciplinaridade se converte, enfim, numa abordagem metodológica facilitadora da transversalidade, constituindo-se como um possível caminho para a integração. Além de ser vista como uma metodologia que tem a vantagem de permitir a participação dos estudantes na escolha dos temas prioritários, "A interdisciplinaridade e a transversalidade complementam-se, ambas rejeitando a concepção de conhecimento que toma a realidade como algo estável, pronto e acabado" (BRASIL, 2011, p. 44).

Embora ocorra um deslocamento da ideia de integração curricular, conforme pensada no projeto de ensino médio integrado, o texto segue afirmando que é importante que as 
atividades integradoras sejam concebidas a partir "do trabalho como primeira mediação entre o homem e a natureza e de suas relações com a sociedade e com cada uma das outras dimensões curriculares reiteradamente mencionadas" (BRASIL, 2011, p. 45). Há uma sugestão para que as chamadas atividades integradoras sejam desenvolvidas a partir de temas que incluam a problemática do trabalho.

Defendemos, com base em Laclau e Mouffe (1987)e Laclau (2013), que esta operação de deslocamento do sentido de interdisciplinaridade e de totalidade, tal como originalmente apresentado no projeto de ensino médio integrado, é, mais uma vez, produzida por meio de uma relação de negociação entre as diferentes demandas que constituem a cadeia de equivalências do discurso de integração no contexto das DCNEM. Estas demandas se traduzem em uma série de ideias, concepções e perspectivas metodológicas que disputam espaços no processo de significação do currículo.

Diante da pluralidade das demandas que constituem a cadeia discursiva do discurso de integração no contexto das DCNEM de 2012, é que sustentamos o argumento de que é importante compreender o jogo de linguagem presente no texto legal, com a intenção de criar equivalências entre propostas que parecem antagônicas e irreconciliáveis. Pois quando as DCNEM reiteram que a organização do currículo obedecerá a princípios unitários, mas poderá adotar diferentes formas de organização, defendemos que isso abre possibilidade para qualquer uma das formas antes citadas, já que a prática é, como enfatiza Ball (1994), um importante contexto no processo de produção da política e não apenas um lugar de implementação das regulamentações produzidas em contextos alheios à mesma.

As várias demandas de integração curricular relacionadas a este último sentido tratado: interdisciplinaridade, totalidade, transversalidade entram em processo de articulação entre si para confrontar o seu "outro antagônico" representado pela organização disciplinar. Entretanto, como elemento excluído da cadeia de equivalência, a disciplinarização, não sendo um elemento neutro, funciona como o exterior constitutivo das identidades articuladas. Aquele algo que a totalidade das identidades articuladas expele de si para se constituir. Portanto, aquilo que ao mesmo tempo em que se constitui na sua possibilidade também se mostra como a sua própria impossibilidade de realização.

Como todas as demandas articuladas não abrem mão de seu particular conteúdo para que alguma delas possa representar de forma plena o conjunto de todas as diferenças, então, o que é possível que se tenha, em última análise, é uma totalidade fracassada. Uma totalidade que constitui um objeto impossível e necessário, ao mesmo tempo. Impossível porque:

[...] a tensão entre equivalência e diferença é algo insuperável; necessário, porque sem o fechamento da cadeia articulatória, por mais precário que venha ser, não haveria condições de fixação de sentidos e nem da emergência de identidades. (LACLAU, 2013, p. 119).

A operação que possibilita que uma diferença assuma, sem deixar de ser uma diferença particular, a representação significativa de uma totalidade incomensurável em torno de um ponto nodal é, finalmente, o que Laclau denomina de hegemonia. A hegemonia ocorre quando uma particularidade assume o lugar de uma universalidade incomensurável, porque o conteúdo diferencial particular passa a ser o significante da plenitude comunitária ausente. Neste ponto 
nos aproximamos daquilo que vimos procurando demonstrar com relação ao processo de significação da integração na política focalizada. Tem a ver com a noção de significantes vazios desenvolvida por Laclau $(2011,2013)$. Para este autor, um significante vazio surge da necessidade de nomear um objeto ao mesmo tempo impossível e necessário de ser nomeado. Assim, "O esvaziamento de um significante particular, de seu particular significado diferencial é o que torna possível a emergência de significantes vazios como significantes de uma falta, de uma totalidade ausente" (LACLAU, 2011, p. 75). Por isso, como condição para própria fixação de sentidos, os significantes vazios se mostram como uma estratégia retórica para significar o que é insignificável, alguma coisa que excede o próprio sistema de significação. A presença de significantes vazios é a própria condição para a fixação de uma hegemonia.

No caso analisado, a fixação de um sentido literal para o significante integração é um horizonte impossível de ser alcançado, pois nenhum dos termos articulados consegue representar plenamente as demandas nas suas particularidades. Resulta daí uma hegemonia precária, devido à necessidade de significar de alguma forma e dar nome à identidade que emerge da prática articulatória. Neste sentido, afirmamos, que em relação aos discursos de integração presentes nas DCNEM de 2012, aquilo que foi possível alcançar por meio do processo articulatório entre as demandas que disputaram a fixação de sentidos encarna uma formação discursiva da ordem de um significante vazio. Um significante que não tem um conteúdo preciso, mas que tenta preencher o espaço aberto da significação. O conteúdo significativo particular permanece habitando cada uma das demandas articuladas e o resultado que obtemos da operação hegemônica é produção de um discurso ambíguo, que desliza nos seus significados, porque não pode representar fielmente nenhuma dos elementos isoladamente.

A tensão entre a equivalência e o confronto antagônico é inerente a qualquer processo político. A cadeia "somente pode viver na instável tensão entre estes dois extremos e se desintegra se um deles se impuser ao outro" (LACLAU, 2013, p. 196). Entretanto, se a cadeia dicotômica se torna imprecisa por meio de uma operação de deslocamento dos antagonismos, os significantes vazios acabam sofrendo uma modificação e se transformam em significantes flutuantes.

Laclau (2013, p. 199) argumenta que as categorias de significantes vazios e significantes flutuantes são estruturalmente diferentes. A primeira "diz respeito à construção de uma identidade popular, uma vez que a presença de uma fronteira estável é dada como certa"; a segunda "tenta apreender os deslocamentos daquela fronteira", ou seja, no segundo caso o "outro" antagônico não permanece imutável, porque ocorre um deslocamento dos antagonismos que não permanecem os mesmos e nem se situam apenas numa posição de exterioridade em relação à fronteira antagônica, como no caso do elemento que foi excluído da cadeia e que representa o inimigo identificável por todas as particularidades articuladas.

Considerando a trajetória do discurso de integração no conjunto da política do ensino médio no período recortado (1998-2012), identificamos a ocorrência de deslocamentos no processo político que possibilitou a fixação de sentidos contingentes para este significante nos textos políticos que compõem o corpus da pesquisa.

Nas DCNEM de 1998 e nos PCNEM, o corte antagônico da integração era a organização disciplinar do currículo. Os conteúdos disciplinares tradicionais, estruturados de maneira 
fragmentada e descontextualizada, se configuravam como um tipo de organização incapaz de responder às demandas da esfera produtiva, especialmente, com relação às exigências de formação para o mundo do trabalho. Naquele contexto, o novo tipo de organização curricular proposto foi o modelo das competências básicas a ser desenvolvido por meio da interdisciplinaridade e da contextualização. Como afirmamos em outro momento, estes foram os significantes privilegiados do discurso de integração nos anos de 1990.

Entre os anos de 2003 a 2012, os discursos de integração passaram a articular outros sentidos em que a fronteira antagônica da integração, antes simbolizada pela disciplinarização do currículo, sofreu alguns deslocamentos em função da não fixidez da relação de antagonismo que configurou este discurso no período anterior. Neste novo contexto, o outro antagônico do discurso de integração não é somente a organização disciplinar fragmentada e descontextualizada, mas a desarticulação entre educação básica e educação profissional (dualismo), a parcialidade da formação voltada para o desenvolvimento de competências para o mercado e para o trabalho, a dissociação entre conhecimentos gerais e conhecimentos específicos na organização do currículo, além, logicamente, de se manter a crítica à disciplinarização sem rechaçar as disciplinas de forma radicalizada.

\section{CONSIDERAÇõES FINAIS}

Procuramos destacar ao longo do trabalho que a integração se constitui num significante de grande centralidade no processo de produção da política curricular brasileira para o ensino médio no decorrer dos anos de 1990-2010. Em torno deste significante se reuniram um grande número de demandas que disputaram hegemonia nos textos curriculares oficiais.

Defendemos que a produção da política curricular pode ser concebida como obra pura e simples do Estado ou de governos em um determinado contexto histórico, mas envolve uma complexa e controversa rede de influências. Buscamos construir uma análise sobre a política do ensino médio a partir do entendimento de que os textos políticos são resultados de lutas políticas travadas em torno da significação do currículo. Uma luta que envolve processos de articulação, negociação e acordos precários e contingentes em torno de diferentes demandas curriculares colocadas por sujeitos e grupos que disputam espaço na política e lutam para hegemonizar seus discursos. Esses sujeitos e grupos atuam em diferentes lugares e competem para controlar as significações no contexto de produção do texto político.

Nesse sentido, buscamos remontar a trajetória do discurso de integração na política brasileira para o ensino médio, tentando apreender os sentidos de integração que foram disputados no contexto de produção dos documentos curriculares, assim como procuramos remontar a cadeia de diferenças e equivalências que formam o discurso de integração no âmbito dos documentos analisados, com a preocupação de destacar os antagonismos e as articulações presentes nessas formações discursivas. Acreditamos que tais articulações e antagonismos podem nos servir como indicadores para novas análises num contexto em que presenciamos a emergência de uma nova reforma curricular que tenta se estabelecer, de forma centralizadora e autoritária, atropelando o processo que deu origem às últimas DCNEM. 
BALL, S. J. Education reform - a critical and post-structural approach. Buckinghan: Open University Press, 1994. BERNSTEIN, B. A estruturação do discurso pedagógico: classe, código e controle. Petrópolis, RJ: Vozes, 1996. BOWE, R.; BALL, S. J.; GOLD, A. Reforming education \& changing school: case studies in policy sociology. London; New York; Routlegde, 1992.

BRASIL. Lei n 9.394. Institui as diretrizes e bases da educação nacional. Brasília, DF: 20 de dezembro de 1996.

. Lei 5.692. Fixa Diretrizes e Bases para o ensino de $1^{\circ}$ e $2^{\circ}$ graus, e dá outras providências. Brasília, DF: 11 de agosto de 1971.

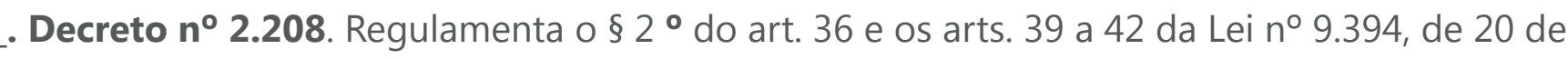
dezembro de 1996, que estabelece as diretrizes e bases da educação nacional. Brasília, DF: 17 de abril de 1997.

- Parâmetros Curriculares Nacionais para o Ensino Fundamental: terceiro e quarto ciclos: apresentação dos temas transversais. Brasília: MEC/SEF, 1998.

. Parecer CNE/CEB n 15/98. Diretrizes Curriculares Nacionais para o Ensino Médio. Brasília, 1998.

. Resolução CNE/CEB 03/98. Diretrizes Curriculares Nacionais para o Ensino Médio. Brasília, 1998.

. Parâmetros Curriculares Nacionais para o Ensino Médio. Brasília: MEC/SEMTEC, 1999.

- Decreto $n^{\circ}$ 5.154. Regulamenta o $\S 2^{\circ}$ do art. 36 e os arts. 39 a 41 da Lei $n^{\circ} 9.394$, de 20 de dezembro de 1996, que estabelece as diretrizes e bases da educação nacional. Brasília, DF: 23 de julho de 2004.

. Parecer CNE/CEB n 7/2010. Diretrizes Curriculares Nacionais Gerais para a Educação Básica. Brasília, 2010.

. Parecer CNE/CEB n 05/2011. Diretrizes Curriculares Nacionais para o Ensino Médio. Brasília, 2011.

Resolução CNE/CEB 02/2012. Diretrizes Curriculares Nacionais para o Ensino Médio. Brasília, 2012.

- Medida Provisória n 746/2016. Institui a política de fomento à implementação de escolas de ensino médio em tempo integral, altera a Leis n 9.394, a Lei n 11.494/2007 e dá outras providências. Brasília, 2016.

. Lei 13.415/2017. Altera a Leis 9.394/69 (LDB), a Lei 11.494/2007, o Decreto-Lei no 5.452/1943 (CLT) e o Decreto-Lei no 236/1967; revoga a Lei no 11.161/2005; e institui a Política de Fomento à Implementação de Escolas de Ensino Médio em Tempo Integral. Brasília, 2017

BERGER FILHO, R. Currículo por competências. Brasília: MEC, 1999. Disponível em: http://www.mec. gov.br/semtec/ensmed/ftp/curriccompet.doc

CIAVATTA, M. A formação integrada: a escola e o trabalho como lugares de memória e de identidade. In: FRIGOTTO, G.; CIAVATTA, M.; RAMOS, M. N. (Orgs.). Ensino médio integrado: concepção e 
contradições. 3 ed. São Paulo: Cortez, 2012. p. 83-106

DELORS, J. Educação: um tesouro a descobrir. 2. ed. São Paulo: Cortez/ Brasília, DF: MEC/UNESCO, 2003.

FRIGOTTO, G.; CIAVATTA, M. (Orgs.). Ensino médio: ciência, cultura e trabalho. Brasília, MEC/SEMTEC, 2004.

FRIGOTTO, G.; CIAVATTA, M.; RAMOS, M. N. (Orgs.). Ensino médio integrado: concepção e contradições. 3. ed. São Paulo: Cortez, 2012.

LACLAU, E.; MOUFFE, C. Hegemonía y estrategia socialista. Hacia una radicalización de la democracia. Madri: Siglo XXI, 1987.

. Emancipação e Diferença. Rio de Janeiro: EdUERJ, 2011.

- A razão populista. São Paulo: Três Estrelas, 2013.

LOPES, A. C. Competências na organização curricular da reforma do ensino médio. Boletim Técnico do SENAC. Rio de Janeiro, v. 27, n³ 3, 2001. Disponível em: http://www.senac.br/ informativo/bts/273/boltec273a

Os parâmetros curriculares nacionais para o ensino médio e a submissão ao mundo produtivo: o caso do conceito de contextualização. Educação \& Sociedade, Campinas, v. 23, n. 80, setembro/2002a, p. 386-400. Disponível em: http://www.cedes.unicamp.br

Parâmetros curriculares para o ensino médio: quando a integração perde o seu potencial crítico. In: LOPES, A.; MACEDO, E. (Orgs.). Disciplinas e integração curricular: história e políticas. Rio de Janeiro: DP\&A, 2002b, p.73-94.

. Políticas de integração curricular. Rio de Janeiro: EdUERJ, 2008.

MACEDO, E. Currículo e Competência. In: LOPES, A.; MACEDO, E. (Orgs.). Disciplinas e integração curricular: história e políticas. Rio de Janeiro: DP\&A, 2002, p. 115-143.

MOURA, D. H. Educação básica e educação profissional: dualidade histórica e perspectivas de integração. In: Anais 30ª Reunião Anual da ANPEd. Anais do evento. Caxambu: ANPEd, 2007.

.Ensino médio e educação profissional no Brasil nos anos 2000: movimentos contraditórios. 2012, 32 p. [mimeo].

RAMOS, M. N. O projeto unitário de ensino médio sob os princípios do trabalho, da ciência e da cultura. In: FRIGOTTO, G.; CIAVATTA, M. (Orgs.). Ensino médio: ciência, cultura e trabalho. Brasília, MEC/SEMTEC, 2004, p. 38-69.

. A Pedagogia das Competências: autonomia ou adaptação? 3. ed. São Paulo: Cortez, 2006.

. Concepção do ensino médio integrado. Ano: 2007. Acesso em: 03 de fevereiro de 2014. http:// forumeja.org.br/go/sites/forumeja.org.br.go/files/concepcao_do_ensino_medio_integrado5.pdf, 26 p.

O currículo para o ensino médio em suas diferentes modalidades: concepções propostas e problemas. Educação \& Sociedade. Campinas, v. 32, n. 116, p. 771-788, jul.-set. 2011. Disponível em: http://www.cedes.unicamp.br 
SAVIANI, D. A nova lei da educação. LDB: limites, trajetórias e perspectivas. 8. ed. São Paulo: Autores Associados, 2003a.

O choque teórico da politecnia. Educação, Trabalho e Saúde. Rio de Janeiro: EPSJV/FIOCRUZ, 2003b.

TORRES SANTOMÉ, J. Globalização e interdisciplinaridade - o currículo integrado. Porto Alegre: Artes Médicas, 1998.

Artigo recebido em: $17 / 10 / 2017$

Aprovado em: 19/01/2018

Contato para correspondência:

Maria Gorete Rodrigues Cardoso.

E-mail: goreterc@ufpa.br

1 A Lei 13.415/17 prescreve regras que alteram substancialmente a LDB no que tange às finalidades e à organização curricular do ensino médio. Define que o currículo será composto por uma Base Nacional Comum Curricular (BNCC) e por itinerários formativos específicos.

2 A BNCC será constituída das áreas de conhecimentos: linguagens, matemática, ciências da natureza, ciências humanas. Os itinerários formativos específicos serão definidos em cada sistema de ensino com ênfase em uma das áreas de conhecimento da BNCC e na formação técnica e profissional.

3 A referida tese está disponível na página do PPGED/UFPA: http://www.ppged.com.br/arquivos/File/ gorete.pdf

4 Dentre os autores que compõem essa comunidade epistêmica de atuação nacional e com os quais procuramos dialogar no desenvolvimento das análises destacam-se: Demerval Saviani; Gaudêncio Frigotto; Maria Ciavatta; Marise Nogueira Ramos; e Dante Henrique Moura.

$5 \quad$ O evento seminal do debate do projeto de ensino médio integrado foi o seminário Ensino Médio: construção política. Deste seminário resultou o livro Ensino Médio: ciência cultura e trabalho, organizado por Gaudêncio Frigotto e Maria Ciavatta, publicado pelo MEC/SEMTEC, em 2004. 